
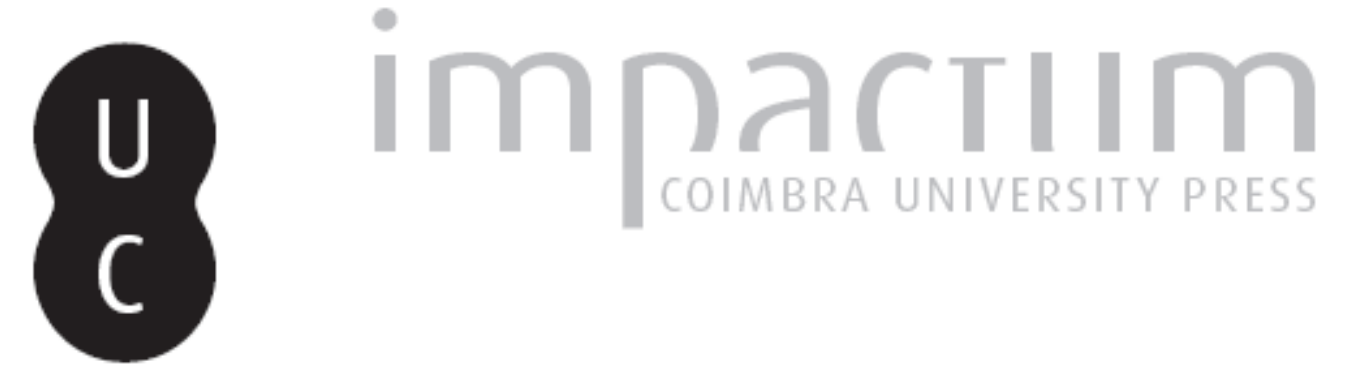

\title{
O Porto e as epidemias: saúde e higiene na imprensa diária em períodos de crise sanitária, 1854-56, 1899 e 1918
}

Autor(es): $\quad$ Almeida, Maria Antónia Pires de

Publicado por: Centro de História da Sociedade e da Cultura

URL persistente:

URI:http://hdl.handle.net/10316.2/39437

DOI:

DOI:http://dx.doi.org/10.14195/1645-2259_12_16

Accessed : $\quad$ 26-Apr-2023 15:39:31

A navegação consulta e descarregamento dos títulos inseridos nas Bibliotecas Digitais UC Digitalis, UC Pombalina e UC Impactum, pressupõem a aceitação plena e sem reservas dos Termos e Condições de Uso destas Bibliotecas Digitais, disponíveis em https://digitalis.uc.pt/pt-pt/termos.

Conforme exposto nos referidos Termos e Condições de Uso, o descarregamento de títulos de acesso restrito requer uma licença válida de autorização devendo o utilizador aceder ao(s) documento(s) a partir de um endereço de IP da instituição detentora da supramencionada licença.

Ao utilizador é apenas permitido o descarregamento para uso pessoal, pelo que o emprego do(s) título(s) descarregado(s) para outro fim, designadamente comercial, carece de autorização do respetivo autor ou editor da obra.

Na medida em que todas as obras da UC Digitalis se encontram protegidas pelo Código do Direito de Autor e Direitos Conexos e demais legislação aplicável, toda a cópia, parcial ou total, deste documento, nos casos em que é legalmente admitida, deverá conter ou fazer-se acompanhar por este aviso.

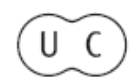


evista de História da Sociedade e da Cultura

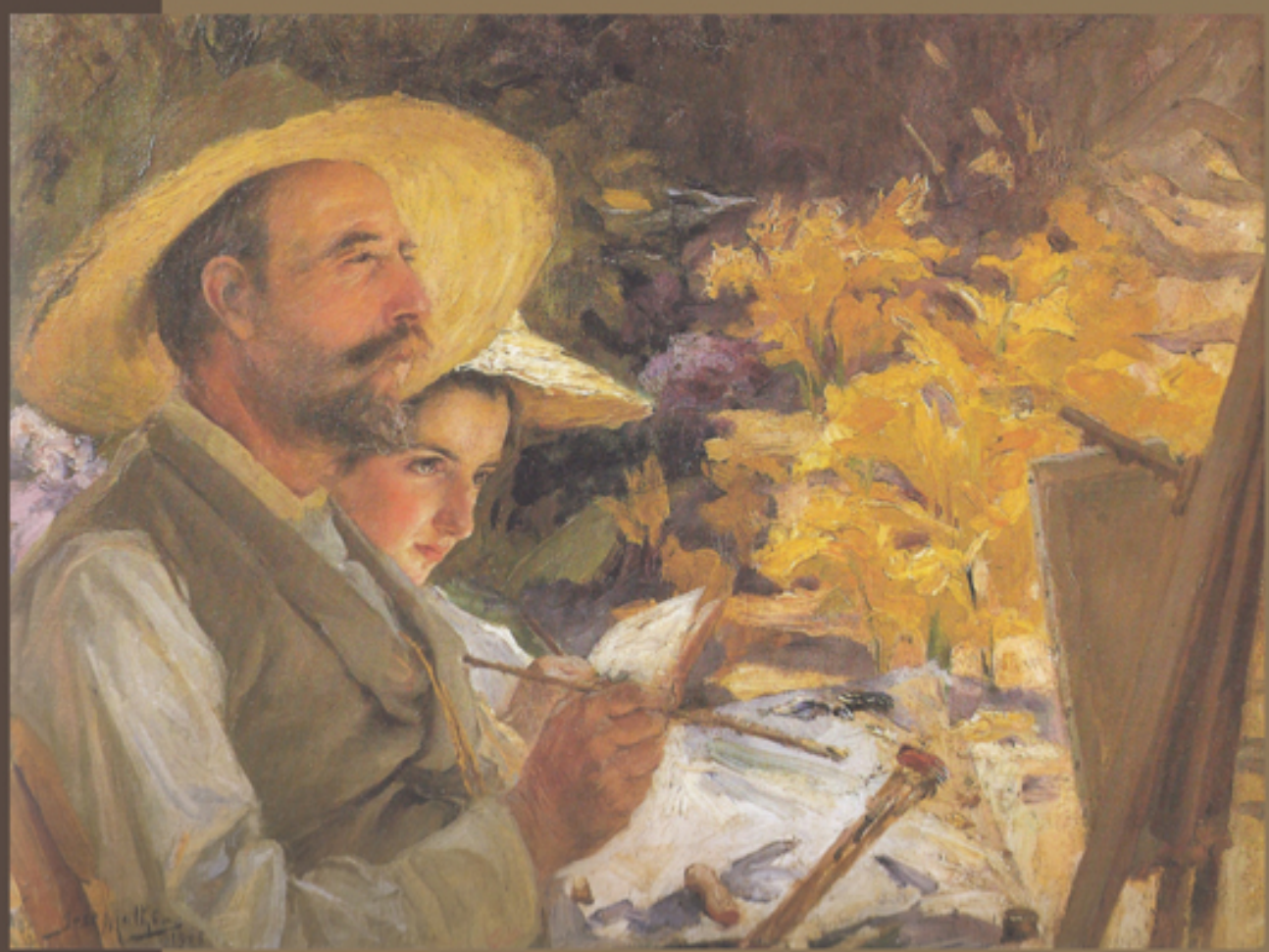

Centro de História da Sociedade e da Cultura Universidade de Coimbra 


\title{
O Porto e as epidemias: saúde e higiene na imprensa diária em períodos de crise sanitária, 1854-56, 1899 e 1918
}

\author{
Maria Antónia Pires de Almeida, PhD \\ Investigadora do CIUHCT, FCT, UNL. \\ map.almeida@fct.unl.pt \\ Texto recebido em /Text submitted on: 15/03/2012 \\ Texto aprovado em /Text approved on: 21/06/2012
}

\section{Resumo/Abstract:}

Em crises sanitárias como as de 1854-56, 1899 e 1918, especialmente no Porto, onde a cólera morbus, a peste bubónica, o tifo exantemático, a gripe pneumónica e a varíola atacaram e mataram percentagens elevadas da população, as imagens das epidemias na imprensa permitem-nos conhecer o estado dos conhecimentos científicos num país que dispunha de conhecimentos e pessoal especializado ao nível dos mais avançados da sua época. Uma base de dados de 6.700 notícias, artigos desenvolvidos e anúncios recolhidos na imprensa diária revela-nos o conhecimento médico e farmacêutico da segunda metade do século XIX e início do XX, o modo como era transmitido a um público não especializado e as soluções apresentadas pelos médicos e pelas autoridades sanitárias.

In times of sanitary crisis in Oporto, such as the cholera morbus epidemic of 1854-56, the bubonic plague in 1899 and the 1918 exanthematic typhus, pneumonic flu and smallpox epidemics, which killed huge percentages of the population, newspapers are important sources to access how scientific knowledge was divulged in a country with specialized professionals who were at the same level as the ones in the most advanced countries in the world. A database of 6.700 news, medical reports and advertisements reveals the state of the art of medical and pharmaceutical sciences in the second half of the nineteenth century and the beginning of the twentieth, the way it was divulged to an unspecialized audience and the solutions presented by doctors and sanitary authorities.

Palavras chave/Keywords:

Epidemias; Medicina; Farmácia; Higiene.

Epidemics; Medicine; Pharmacy; Hygiene.

* Este texto é uma adaptação da comunicação "O Porto e as epidemias: divulgação dos conhecimentos médico e farmacêutico em períodos de crise sanitária" apresentada no Congresso Luso-Brasileiro de História das Ciências, sessão 3: «As ciências médico-farmacêuticas no universo lusófono», Coimbra, 26 a 28 de Outubro de 2011. 


\section{Introdução}

Em períodos de crise sanitária grave como os que ocorreram em 1854-56, 1899 e 1918, especialmente no Porto, onde a cólera morbus, a peste bubónica, o tifo exantemático, a gripe pneumónica e a varíola atacaram e mataram percentagens elevadas da população, as imagens das epidemias na imprensa permitem-nos conhecer o estado dos conhecimentos científicos da época. Uma base de dados de mais de 6.700 notícias, artigos desenvolvidos e anúncios sobre Ciência e Tecnologia recolhidos nos jornais diários de maior circulação dá-nos a possibilidade de desenvolver os temas do conhecimento científico médico e farmacêutico da segunda metade do século XIX e início do XX, o modo como ele era transmitido e divulgado ao público, as preocupações suscitadas em períodos de crises sanitárias e as soluções apresentadas pelos médicos e pelas autoridades sanitárias.

Os temas da saúde e da higiene surgiram como o principal fator de interesse por se sobreporem a todos os outros, ocupando uma maioria significativa de $64 \%$ no conjunto das notícias e anúncios recolhidos, abrangendo tanto os períodos de epidemia declarada como os outros de relativa normalidade a nível sanitário. Em períodos de crise esta percentagem aumentava significativamente, como aconteceu em outubro de 1918, no auge da gripe pneumónica, quando as notícias e anúncios atingiram os $90 \%$. Salientam-se os períodos de epidemia declarada por constituírem não só oportunidades únicas para a observação das sociedades e dos momentos históricos ${ }^{1}$, mas também, para a recolha privilegiada dos conhecimentos médicos e farmacêuticos das respetivas épocas, contribuindo assim com dados úteis para a História da Medicina e da Farmácia em Portugal e respondendo a questões sobre o modo como as suas práticas foram introduzidas na vida diária das famílias e da sociedade.

O principal objetivo é analisar o modo como o conhecimento científico chegava ao cidadão comum, utilizando a imprensa generalista como fonte principal. Tendo em conta o acesso limitado à escrita por parte da maioria da população portuguesa, numa altura em que os níveis de analfabetismo

1 ROSENBERG, Charles E. - The Cholera Years: The United States in 1832, 1849 and 1866. Chicago and London: The University of Chicago Press, 1987. 
de pessoas com mais de seis anos eram calculados em cerca de $80 \%$ em $1878^{2}$, pode, contudo, afirmar-se que a leitura da imprensa aumentou consideravelmente ao longo do século XIX e início do XX, contribuindo para a formação de audiências interessadas e das representações que a sociedade tinha do conhecimento e da ciência. Não só a leitura direta, mas a leitura oral e coletiva em espaços públicos de sociabilidade, como as tabernas e os mercados, ou mesmo a sua divulgação pelos padres na missa do domingo, o que permite estimar uma audiência superior à tiragem dos mesmos.

Em períodos de crise sanitária, as imagens das epidemias na imprensa, os comentários, as citações de outros jornais nacionais e internacionais, assim como de livros e revistas científicas, permitem-nos aferir a posição de Portugal, um país considerado periférico, e a dos seus cientistas e especialistas nas mais diversas áreas, entre os restantes países europeus. Verifica-se que o país dispunha de tantos conhecimentos e pessoal especializado como os países mais avançados da sua época ${ }^{3}$, se bem que com grandes discrepâncias entre os grandes centros (Lisboa e Porto) e a periferia, sobretudo a nível da distribuição e aplicação dos recursos e do pessoal médico e auxiliar.

Os jornais consultados foram: $O$ Comércio, diário publicado no Porto entre 2 de junho de 1854 e 30 de julho de 2005, que em 1856 mudou o nome para $O$ Comércio do Porto; O Ecco Popular, também do Porto, publicado diariamente entre 1847 e 1860; O Século, jornal diário de Lisboa, publicado entre abril e dezembro de 1855 , data em que interrompeu a sua publicação; um novo jornal com o mesmo nome foi publicado entre 1881

2 CASCÃO, Rui - Em casa: o quotidiano familiar in VAQUINHAS, Irene (coord.), A Época Contemporânea, in MATTOSO, José (dir.), História da Vida Privada em Portugal, vol. III. Lisboa: Círculo de Leitores, 2011, p. 222-252.

3 Por exemplo, o médico Bernardino António Gomes (1768-1823), pelos seus trabalhos de "controlo da doença no sentido da sua prevenção" pode ser colocado ao nível de Pasteur, Koch e Roux, que "desenvolveram a farmacoterapia e recorreram ao experimentalismo e contribuíram para uma nova ordem cognitiva e terapêutica", PEREIRA, Ana Leonor, PITA, João Rui - Ciências in MATTOSO, José (ed.), História de Portugal, vol. V. Lisboa: Círculo de Leitores, 1993, p. 653-667. Assim como mais tarde Câmara Pestana e Ricardo Jorge, cujos trabalhos nas áreas da higiene e epidemiologia foram reconhecidos e elogiados a nível nacional pelos seus pares e pelo poder político, e também a nível internacional. Ver também BASTOS, Cristiana, BARRETO, Renilda (orgs.) - A Circulação do Conhecimento: Medicina, Redes e Impérios. Lisboa: Imprensa de Ciências Sociais, 2011, p. 31-32. 
e 1977; finalmente o Diário de Notícias, também de Lisboa, o mais antigo jornal diário ainda em circulação, fundado em 29 de dezembro de 18644.

Figura I - Jornais consultados

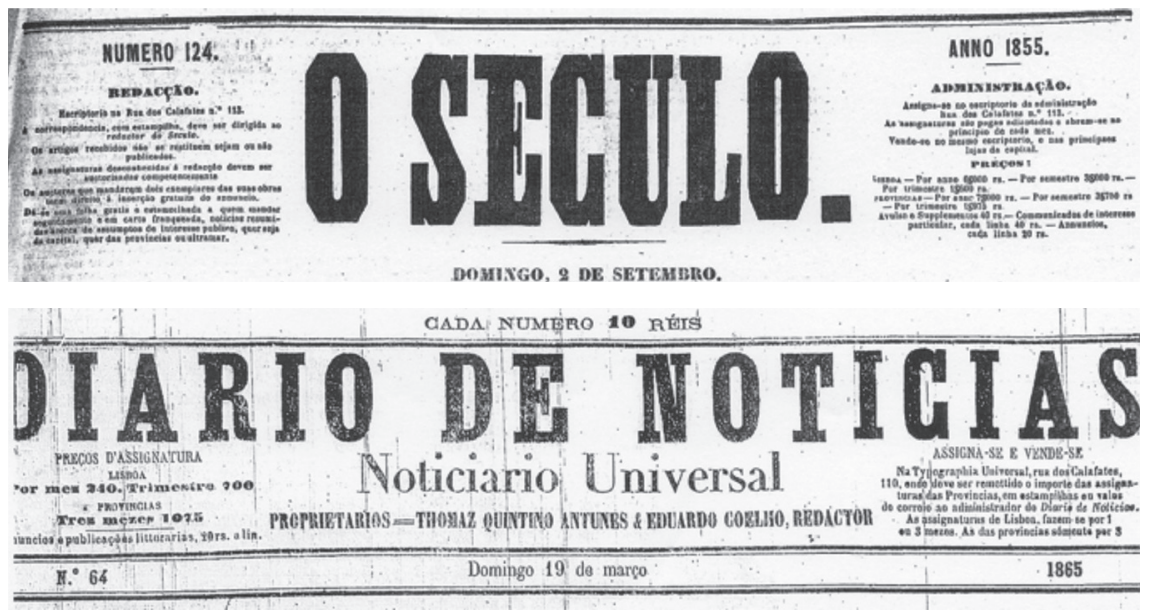

\section{Epidemias no século XIX}

A divulgação das informações sobre saúde pública, especialmente em períodos epidémicos, era uma questão de sobrevivência. Ao longo do século XIX tomou-se consciência, pela experiência traumática das sucessivas pandemias, que a prevenção e cada vez mais a higiene eram os meios mais eficazes para lidar com as crises sanitárias. O discurso higienista introduziu a Medicina na vida privada ${ }^{5}$ as autoridades aplicaram-no para lutar contra as epidemias, usando-o nos relatórios oficiais que eram publicados na íntegra nos periódicos generalistas. Sem este recurso os médicos e as autoridades sanitárias teriam perdido as sucessivas batalhas contra as doenças em que o mundo inteiro estava envolvido. Não apenas em resposta às epidemias, mas também no combate às doenças endémicas que causavam altos níveis

4 Foi seguido pelo diário do Porto O Primeiro de Janeiro, fundado em 1869 e ainda em publicação.

5 FERREIRA, Luiz Otávio - Os periódicos médicos e a invenção de uma agenda sanitária para o Brasil (1827-43). História. Ciências. Saúde-Manguinhos, Out., vol. 6, n. 2 (1999) 331-351. 
de mortalidade, condicionando a economia e todos os aspetos da vida das pessoas, das cidades e dos países ${ }^{6}$.

Chegar à idade adulta e sobreviver mais alguns anos era obra considerável até ao século XX. Desde logo, se os recém-nascidos não morriam logo de “debilidade congénita", muitos ficavam órfãos logo à nascença, nos casos bastante frequentes de morte das mães na altura do parto ou pouco tempo depois com febres puerperais, típicas das infeções pós-parto, que eram fatais já que não havia antibióticos. Nestas situações as hipóteses de sobrevivência do recém-nascido diminuíam, a menos que se providenciasse uma ama-de-leite que cumprisse os requisitos mínimos de salubridade. Ao longo da infância a sucessão de doenças era praticamente inevitável: raquitismo, paralisia infantil, sarampo (e suas derivadas, como a varicela, rubéola, papeira), difteria, tosse convulsa (coqueluche), meningite, escarlatina e poliomielite, eram "grandes responsáveis pela mortalidade até ao primeiro ano de vida" . A somar a estas, doenças endémicas como a tuberculose, sífilis, lepra, febre tifóide e malária (as chamadas "sezões" ou "febres intermitentes"), tétano, lúpus; doenças sazonais como as gripes, gastrites, enterites e disenterias; e ainda algumas ocasionais como a sarna, a raiva (hidrofobia), a febre da carraça, a gonorreia, a leishmaniose, a brucelose (ou febre de Malta, transmitida pelas ovelhas) e o carbúnculo (antraz) dizimavam grande parte da população adulta.

Acrescentam-se ainda a asma e algumas doenças que ainda nem tinham sido identificadas, como a hepatite, a cirrose, ou a diabetes ${ }^{8}$. Também o cancro era referido de forma geral e mal definida, apesar de já em 1865, por exemplo, ter sido objeto de teses na Escola Médico-Cirúrgica de Lisboa9 Num anúncio de um "unguento milagroso" percebe-se a confusão entre doenças tão diferentes: "cura cancros, alporcas, antrazes e toda a qualidade de

6 PELLING, Margaret - Cholera, fever and English medicine, 1825-1865. Oxford: New York, Oxford University Press, 1978.

7 VAQUINHAS, Irene (coord.) - A Época Contemporânea ..., cit., p. 376.

8 A insulina só foi isolada em 1921 por Banting, Best e Macleod, que foram premiados com o Prémio Nobel em Fisiologia em 1923.

9 "Anteontem defendeu brilhantemente a sua tese, acerca do cancro do fígado, na escola de medicina de Lisboa, na travessa da Porta do Carro, a S. Lázaro, o distinto académico Sr. João Cesário de Lacerda, moço a quem as letras já devem não pouca dedicação", Diário de Notícias, 26/07/1865. 
chaga ou ferida por mais antiga que seja"10 . A somar a isto tudo, os "flagelos sociais", como o alcoolismo, uma patologia que "enfraquecia a raça"

Perante tal cenário, e considerando a falta de conhecimentos e de condições materiais para combater estas doenças que debilitavam as populações, podemos calcular o impacto das grandes pandemias do século XIX. Para além das habituais epidemias de peste negra, febre-amarela e varíola, este século viu surgir pela primeira vez na Europa e depois espalhadas pelo mundo inteiro as agressivas epidemias de cólera. Esta epidemia alterou de forma significativa o modo de encarar as doenças por parte do poder político. A sua influência no desenvolvimento de políticas sanitárias foi fundamental e resultou na criação de novos conceitos de higiene e saúde pública que ainda hoje vigoram. Devido aos trabalhos de John Snow e à identificação da causa da difusão da doença é que se avançou para obras de saneamento básico.

Os Estados reagiram às epidemias por vezes de forma divergente, com medidas restritivas que privilegiavam os cordões sanitários e as quarentenas, e que tinham consequências económicas por vezes tão devastadoras como a própria doença. A comunidade médica internacional, se bem que beneficiasse de uma circulação regular do conhecimento, verificou a falta de capacidade de resposta prática à doença. A partir de 1851 as potências europeias começaram a enviar os seus melhores especialistas a Conferências Sanitárias Internacionais que visavam a uniformização das medidas sanitárias a pôr em prática. Estas conferências, iniciadas em Paris e repetidas em Constantinopla em 1866, Viena em 1874, Washington em 1881, Roma em 1885, Veneza em 1892, Dresden em 1893 e de novo em Veneza em 1897, revelaram "um conhecimento científico em constante mutação" e "posições nacionais divergentes e mutáveis ao longo do tempo. As grandes potências europeias - Inglaterra, França e mais tarde a Alemanha - posicionaram-se

${ }^{10}$ Diário de Notícias, 04/11/1865. Alporca é o mesmo que escrófula: é uma inflamação de gânglio linfático que está associada à tuberculose. Antraz ou carbúnculo é provocado por uma bactéria.

${ }^{11}$ CORREIA, Fernando da Silva Correia - Portugal Sanitário (Subsidios para o seu estudo). Lisboa, Ministério do Interior - Direção Geral de Saúde Pública, 1938. 
em campos por vezes antagónicos pressionando os países mais pequenos e periféricos a prescindirem da severidade das medidas quarentenárias"12.

Em todas estas conferências, para além da identificação das doenças e respetivas medidas profiláticas e tratamentos, que eram recomendadas aos Estados para a aplicação de medidas uniformizadas, a discussão centrava-se na questão do contágio, que não era consensual. Durante séculos o contágio das doenças fora defendido e apoiado pelos Estados quando estabeleceram as primeiras quarentenas ${ }^{13}$. Porém, o século XIX viu surgir uma nova geração de cientistas que negaram o contágio das doenças, baseando-se na ineficácia das quarentenas e dos cordões sanitários. Os cientistas defensores do "anti-contagionismo" lutaram pela liberdade do indivíduo e do comércio. Verificou-se assim, numa clara associação entre teorias anti-contágio e interesses comerciais, que os governos do norte da Europa, mais liberais e progressistas, avançaram com políticas higienistas, abolindo quarentenas e cordões sanitários, enquanto os do sul da Europa, mais conservadores, mantiveram as práticas correspondentes à teoria do contágio. O Porto, uma cidade liberal, mercantil e em pleno desenvolvimento industrial e comercial, reagiu violentamente contra a autoridade da capital, que o obrigou ao cordão sanitário em todos os períodos epidémicos. E os seus jornais, por lealdade política e dependência económica, fizeram sempre uma campanha forte e persistente contra as medidas autoritárias impostas pela capital, na qual eram secundados pelos jornais de Lisboa, que reproduziam as notícias dos jornais do Porto e as respetivas posições contra as restrições sanitárias. Esta posição, especialmente do Diário de Notícias, justifica-se pelo facto de, em período de epidemia, as informações estarem bastante restringidas pela falta de liberdade de circulação das pessoas. Assim, os jornais tinham apenas acesso às informações que os outros jornais publicavam, à correspondência dos leitores e aos relatórios oficiais.

${ }^{12}$ GARNEL, Rita - Portugal e as Conferências Sanitárias Internacionais (Em torno das epidemias oitocentistas de cholera-morbus). Revista de História da Sociedade e da Cultura, 9 (2009) 229-251.

${ }^{13}$ ACKERKNECHT, E. H. - Anticontagionism between 1821 and 1867. Bulletin of the History of Medicine, 22 (1948) 562-593. 
Esta cidade apresentava condições especiais para o desenvolvimento das doenças, por ter uma indústria crescente e uma população de grande mobilidade a viver nas piores condições de salubridade. No final do século XIX os problemas da cidade do Porto persistiam de tal maneira que Ricardo Jorge apelidou-a "cidade cemiterial". Na sua obra de 1899 Demografia e Higiene da Cidade do Porto: clima, população, mortalidade, o autor aprofundou a questão das ilhas como causa para a proliferação de doenças e epidemias, com especial destaque para a tuberculose ${ }^{14}$. Este seu trabalho ajudou a influenciar a Rainha D. Amélia na criação, nesse mesmo ano, da Assistência Nacional aos Tuberculosos e na construção de sanatórios para os doentes ${ }^{15}$.

Em 1918 a situação não melhorara. O mesmo Ricardo Jorge, nesta altura Diretor-Geral da Saúde e diretor do Instituto Central de Higiene, descreveu num relatório oficial a situação do Porto perante a epidemia de tifo exantemático: a doença tem como "predileção as classes ínfimas, mal alojadas, mal tratadas e mal mantidas" ". Nas ilhas do Porto, como nas casas de malta do sul, os operários e os trabalhadores eventuais dormiam à vez na mesma enxerga, em quartos partilhados, sem acesso a água corrente ou saneamento básico. Esta situação manteve-se: em 1950 as estatísticas de higiene, das comodidades domésticas e das condições sanitárias das casas em Portugal ainda podiam ser consideradas "calamitosas" 17 . Sem dúvida a curva demográfica da população portuguesa só começa a subir significativamente quando os problemas de saúde pública começam a ser resolvidos, numa conjunção entre políticas de saneamento básico, tratamento de águas, programas de vacinação e higiene escolar e introdução dos antibióticos na vida das populações, especialmente a partir do final da Segunda Guerra Mundial.

Em todo o caso, as medidas de prevenção das doenças, com ênfase na higiene, sempre foram as mais divulgadas em períodos de risco sanitário e

${ }^{14}$ JORGE, Ricardo - Demographia e hygiene da cidade do Porto: clima-população-mortalidade. Porto: Repartição de Saúde e Hygiene da Câmara, 1899.

${ }^{15}$ ALMEIDA, António Ramalho de - A tuberculose: doença do passado, do presente e do futuro. Porto: Bial, 1995.

${ }^{16}$ Diário de Notícias, 21/02/1918.

${ }^{17}$ CASCÃO, Rui - Modos de habitar in VAQUINHAS, Irene (coord.) - A Época Contemporânea ..., cit., p. 22-55. 
a comunidade científica em conjunto com a classe política esforçaram-se por educar as populações nesse sentido. Sem dúvida que a colaboração da imprensa generalista foi fundamental nessa divulgação, na sua qualidade de meio privilegiado de acesso ao público.

\section{Cólera}

Durante a epidemia de cólera de 1855 em Portugal, os pobres estavam doentes por sua própria culpa, porque tinham vícios e comportamentos repreensíveis. Era verão, estava calor, e eles expunham-se ao sol que era mortífero. Assim, todas as medidas sanitárias decretadas pelas autoridades, especialmente no Porto, onde se impôs a quarentena aos navios e ao trânsito e a proibição dos mercados, foram vistas como desnecessárias. Especialmente importante: era preciso restabelecer a liberdade do comércio.

Esta controvérsia dominou as páginas dos jornais desde 1854 a $1856^{18}$. A epidemia de cholera morbus foi um tema favorito, e as notícias da sua evolução, tanto na Europa e no resto do mundo, como em Portugal, foram consideradas essenciais. Esta epidemia atingiu especialmente o Porto e a região norte de Portugal em 1855, assim como o Algarve, e no ano seguinte chegou a Lisboa e às ilhas. A maioria dos jornais dedicou grande atenção a esta doença, divulgando as medidas sanitárias e as preocupações das autoridades públicas, além de emitir opiniões sobre as mesmas.

O estado atual dos conhecimentos identifica a cólera como causado pela bactéria Vibrio cholerae (identificado por Robert Koch em 1883). A sua transmissão faz-se por meio de águas ou alimentos contaminados. A prevenção resume-se à adopção de medidas de saneamento básico: a desinfeção das águas com cloro, que foi posta em prática na Europa e na América do Norte ao longo do século XX, extinguiu a doença nestas regiões do globo, se bem que noutras, onde estas medidas continuam a ser de mais difícil execução, a doença ainda surja com gravidade. A origem da

${ }^{18}$ ALMEIDA, Maria Antónia Pires de-A epidemia de cólera de 1853-1856 na imprensa portuguesa. História, Ciências, Saúde-Manguinhos, vol. 18, n. 4, Rio de Janeiro, out./dez. (2011) 1057-1071. IDEM - The Portuguese cholera morbus epidemic of 1853-56 as seen by the press. Notes \& Records of The Royal Society, March 20, n. 66 (1) (2012) 41-53. 
cólera encontra-se na Ásia, mais propriamente no Rio Ganges, a partir do qual se espalhou por todo o mundo pelas rotas comerciais. Chegou primeiro à Rússia, de onde se propagou para a Europa e daí para a América. Esta primeira vaga da epidemia chegou a Portugal em 1833, mais precisamente ao Porto, a bordo do vapor London Marchant, com o general Solignac e 200 soldados belgas, vindos de Ostende para ajudar os Liberais na Guerra Civil ${ }^{19}$. Durante o Cerco do Porto, e depois quando se espalhou pelo país, a epidemia de cólera acabou por causar mais de 40.000 mortos, um número mais elevado do que o da própria guerra.

A segunda grande vaga epidémica começou em Paris em 1849 e espalhou-se para Londres. E a terceira, entre 1852 e 1860, causou mais de um milhão de mortes, afetando sobretudo a Rússia. Foi quando esta epidemia de cólera chegou a Inglaterra que foram dados os primeiros passos para a identificação e prevenção da doença: em 1854 o médico John Snow verificou que 500 casos mortais ocorridos em 10 dias na zona central de Londres resultavam de beber água na bomba de Broad Street. Fechou a bomba e em poucos dias o foco epidémico cessou. Foi a primeira observação válida sobre a transmissão da afeção, que até então se considerava ter como veículos os "miasmas" e o ar em geral. Com a colaboração de Henry Whitehead, um pastor anglicano, Snow estabeleceu a relação direta entre as bactérias e a doença.

Depois de se espalhar por toda a Europa e pelo Mediterrâneo, Canadá, Estados Unidos e as ilhas das Caraíbas em 1853, esta epidemia de cólera chegou a Portugal em dezembro pela fronteira norte. Em maio de 1854 começaram a morrer pessoas e as medidas de quarentenas foram postas em prática. Em setembro de 1854 as cidades portuguesas de fronteira começaram a tomar medidas preventivas, para evitar o contágio de Espanha. E os jornais começaram a alertar as autoridades sanitárias para limpar as cidades e tomar as medidas aconselhadas pela higiene. A cólera acabou por penetrar em Portugal pelo Rio Douro, infetando com gravidade as vilas ribeirinhas a partir de maio. Imediatamente o Porto foi isolado: nenhum barco podia chegar pelo rio à cidade, sem passar pelo lazareto montado

${ }^{19}$ GOMES, Bernardino António - Aperçu historique sur les épidémies de choléra-morbus et de fièvre jaune en Portugal, dans les années de 1833-1865. Constantinople: Imprimerie Centrale, 1866. 
uns quilómetros antes e cumprir a quarentena. Os protestos começaram logo nos jornais portuenses contra este "verdadeiro atentado à liberdade do comércio" e contra as "medidas ineptas, que muito prejudicam o público, e especialmente a classe comercial" 20 , e que ainda por cima permitiam a passagem das pessoas por via terrestre.

O Porto preparou-se para a invasão da epidemia, montando hospitais especiais e distribuindo panfletos explicativos das medidas de higiene. As feiras e os mercados foram proibidos em junho de 1855: considerando que esta era a base da atividade económica da região, os produtores poderiam ir à falência se não colocassem os seus produtos, o que constituía "uma calamidade superior à transmissão do mal, porque o mal resultante é muito maior aumentando a miséria" ${ }^{21}$. Nesta fase abundaram os artigos desenvolvidos com conselhos de higiene para limpeza das casas e das ruas e os anúncios de livros e tratados práticos de Medicina especializados em cólera, com instruções para prevenir e tratar a doença antes da chegada do médico, incluindo os tratados homeopáticos, tão em voga na altura e amplamente divulgados nas páginas dos jornais.

Em geral a imprensa deste período tentou encontrar explicações científicas e racionais para o flagelo a que se assistia, divulgou as medidas higiénicas e criticou vigorosamente os costumes populares, em especial os religiosos. Entre as causas conhecidas para a doença, a pobreza parecia ser a que reunia maior unanimidade. De facto, os pobres eram sempre os primeiros a morrer nestas epidemias e os que tinham maiores taxas de mortalidade.

\section{Peste Bubónica}

Em 1899 declarou-se no Porto uma epidemia de Peste Bubónica, diagnosticada pelo Professor de Higiene e Medicina Legal da Escola Médico-Cirúrgica do Porto, Dr. Ricardo Jorge, na altura médico municipal e diretor do posto de desinfeção pública do Porto, e verificada por vários médicos estrangeiros que se deslocaram a Portugal para estudar a doença.

\footnotetext{
${ }^{20}$ O Comércio, $16 / 05 / 1855$.

${ }^{21}$ O Comércio, 01/08/1855.
} 
Em 24 de agosto de 1899 foi estabelecido um cordão sanitário à volta do Porto, cercado pelas autoridades militares, que foi levantado em 22 de dezembro. Os jornais diários transcreveram todo o processo científico de apuramento dos diagnósticos: autópsias, inoculação de ratos, etc. Os relatórios do Prof. Ricardo Jorge foram minuciosamente reproduzidos nos jornais diários, com o objetivo de alertar os leitores para o perigo real da doença, que não foi bem aceite.

Figura II - O Cordão Sanitário, O Comércio do Porto, 26/08/1899

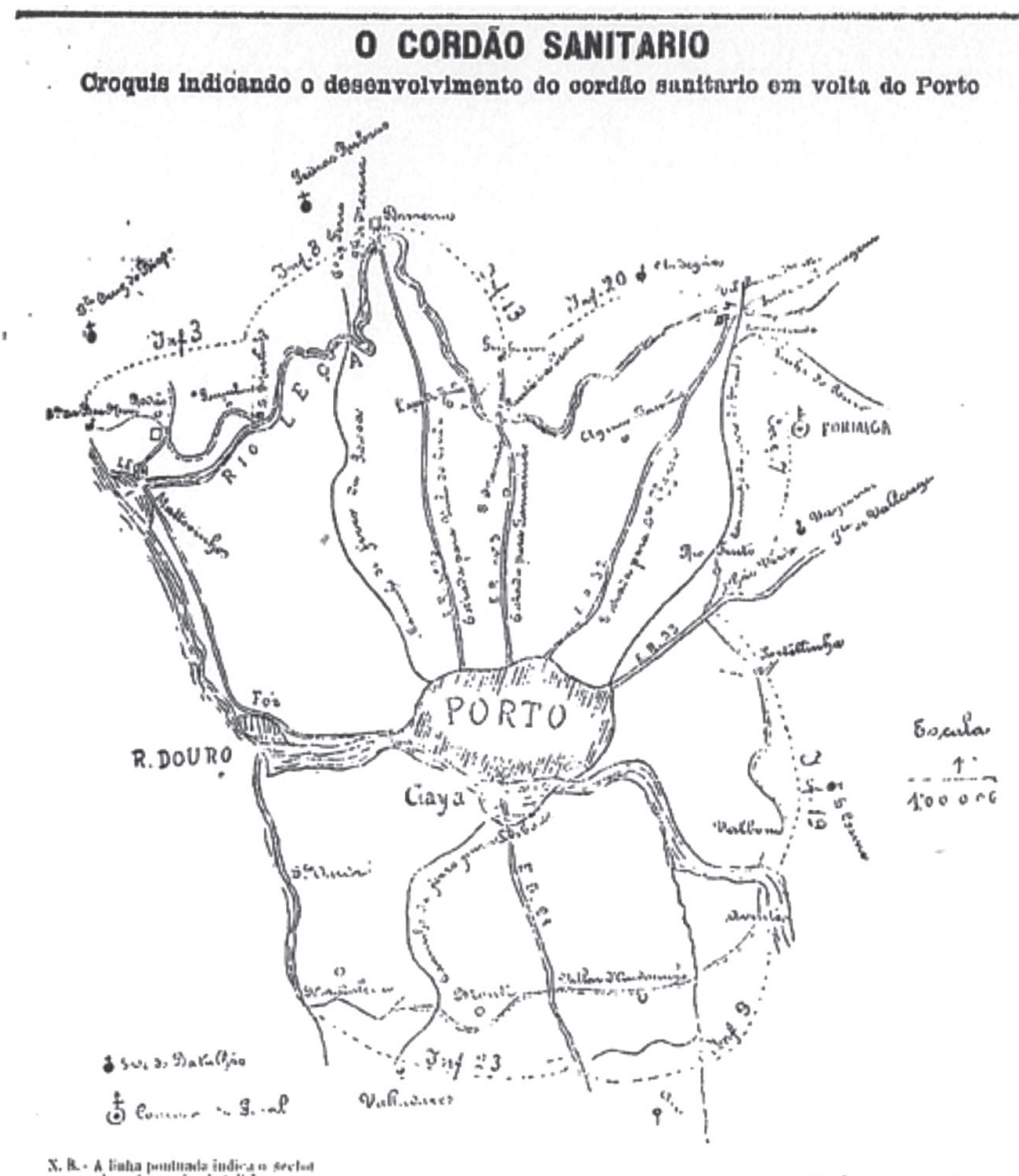

X. R. A thatha poutuata indirsen serled

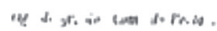

Pelo presente creguio feito no quartel-geveral, o cordis sanitario em voliu do Pcrto nttinge o suguinte desenvolvi. meato: Ao norte: da Beabora da Boa Nova a Barreiros, keudo a liuba gaarnesidy pelas batalhoes de infusteria

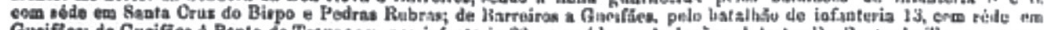

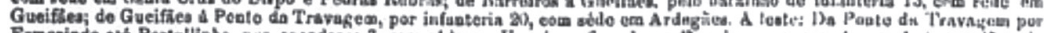

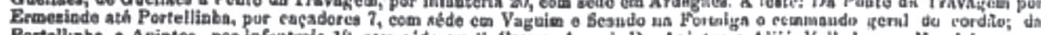

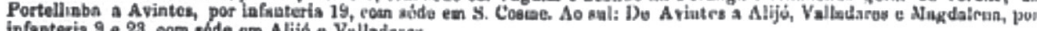
infanteris 9 e 28, com sode cm Alijó e Vulladeres. 
O único tratamento conhecido na altura era o soro Yersin, produzido no Instituto Pasteur de Paris, que foi logo encomendado, apesar da opinião de Ricardo Jorge que este soro não dava "os resultados lisonjeiros que a princípio se divulgaram"22. A sua eficácia dependia da rapidez da aplicação, logo nos primeiros dias da doença, e funcionava melhor ainda como preventivo, como foi usado pelos médicos franceses que se deslocaram ao Porto para estudar a evolução da epidemia ${ }^{23}$.

Apesar do soro, Ricardo Jorge conhecia bem as condições em que a doença se desenvolvia e os grupos mais afetados: "As classes trabalhadoras, miseráveis e mais imundas, ou nos seus hábitos ou na casa em que residem"24. Por esse motivo, foram imediatamente postas em práticas medidas sanitárias rigorosas obrigando à higiene pessoal (com a construção de balneários públicos) e para o combate aos agentes transmissores da doença: os ratos e as pulgas. Um pormenor interessante do combate à epidemia foi a caça aos ratos e aos gatos, que fez as crianças do Porto e de Lisboa ganharem algum dinheiro: por cada rato grande entregue numa esquadra de polícia recebiam 20 réis, por cada pequeno 10, o que motivou uma colheita diária considerável ${ }^{25}$. Ao mesmo tempo suprimiram-se todos os comboios de recreio, todas as "feiras, romarias e outros ajuntamentos", e obrigou-se a inspeção médica de todos os passageiros e empregados dos comboios, que tinham de cumprir uma quarentena de nove $\operatorname{dias}^{26}$. A grande aposta de

${ }^{22}$ Diário de Notícias, 18/08/1899.

23 “o Dr. Calmette, delegado do Instituto Pasteur, de Paris, veio estudar a epidemia da peste bubónica. O ilustre bacteriologista, que é uma notabilidade científica francesa (vem acompanhado do) Dr. Salimbeni, preparador ajudante do Dr. Roux, no Instituto Pasteur", Diário de Notícias, 03/09/1899. Estes e outros médicos de várias nacionalidades realizaram visitas de estudo ao Porto e escreveram relatórios sobre a doença e o modo como foi tratada: CALMETTE, A., SALIMBENI, A. - La Peste Bubonique - Etude de l'Epidémie d'Oporto en 1899. Annales de l'Institut Pasteur (1899) 865-936. MONTALDO y PERÓ, Federico La peste bubónica en Oporto (Portugal) 1899-1900: hecho epidemiográficos e investigaciones clínicas recogidos personalmente y anotados por el Doctor F. Montaldo... que asistió en la epidemia, durante tres meses, como Delegado Médico del Gobierno de España: memoria oficial. Madrid: Establ. Tip. de Portanet, 1900. FERRÁN y CLUA, J., VIÑAS y CUSÍ, F., GRAU, R. - La Peste bubónica: memoria sobre la epidemia ocurrida en Porto en 1899. Barcelona: Tip. Sucesor F. Sánchez, 1907.

${ }^{24}$ Diário de Notícias, 18/08/1899.

${ }^{25}$ Diário de Notícias, 15/10/1899.

${ }^{26}$ Diário de Notícias, 18/08/1899. 
Ricardo Jorge foi na prevenção da disseminação da doença, isolando os doentes e a própria cidade.

A maior urgência das autoridades era delimitar os focos de infeção. De facto, as medidas radicais postas em prática por Ricardo Jorge logo nos primeiros dias do surto epidémico delimitaram o contágio da doença, que teve uma mortalidade reduzida ${ }^{27}$. No entanto, os banhos obrigatórios, as casas e roupas queimadas quando os médicos e os subdelegados de saúde realizavam visitas domiciliárias, acompanhados pela polícia, e encontrava um doente de peste, e o isolamento forçados dos doentes e de todos os seus familiares e vizinhos em hospitais especiais, todas estas ações eram motivo de grande revolta popular, que provocaram cenas de autêntica guerra civil. Apesar do apoio dos médicos do Porto, Ricardo Jorge acabou por se demitir e pedir transferência para Lisboa $^{28}$. Câmara Pestana ainda continuou no Porto a estudar a peste bubónica e acabou por ser infetado e morrer em Lisboa no dia 15 de novembro de 1899, apesar de também ter sido vacinado com o soro ${ }^{29}$. Mas o combate contra a disseminação da epidemia estava ganho e a doença foi considerada extinta em janeiro de 1900.

Uma inovação importante neste período foi uma máscara profilática facial inventada pelo médico Afonso de Lemos para ser usada por médicos e enfermeiros na observação e tratamento dos doentes de peste. Considerando que foi apenas em 1918, durante a epidemia de gripe, que as máscaras faciais foram popularizadas, este aparelho é demonstrativo da criatividade dos médicos portugueses.

${ }^{27} 326$ casos, dos quais 111 óbitos, Diário de Notícias, 31/01/1900.

${ }^{28}$ ALMEIDA, Maria Antónia Pires de - Ricardo Jorge. Biografias de Cientistas e Engenheiros Portugueses. Lisboa: CIUHCT (2011), (http://ciuhct.com/index.php/pt/ biografias/345-jorge-ricardo-almeida.html, consultado em 2012.06.08).

${ }^{29}$ IDEM - Luís da Câmara Pestana. Biografias de Cientistas e Engenheiros Portugueses. Lisboa: CIUHCT (2011), (http://ciuhct.com/index.php/pt/biografias/330-camara-pestana-luis. html, consultado em 2012.06.08) 
Figura III - Máscara facial profilática, Diário de Notícias, 24/08/1899

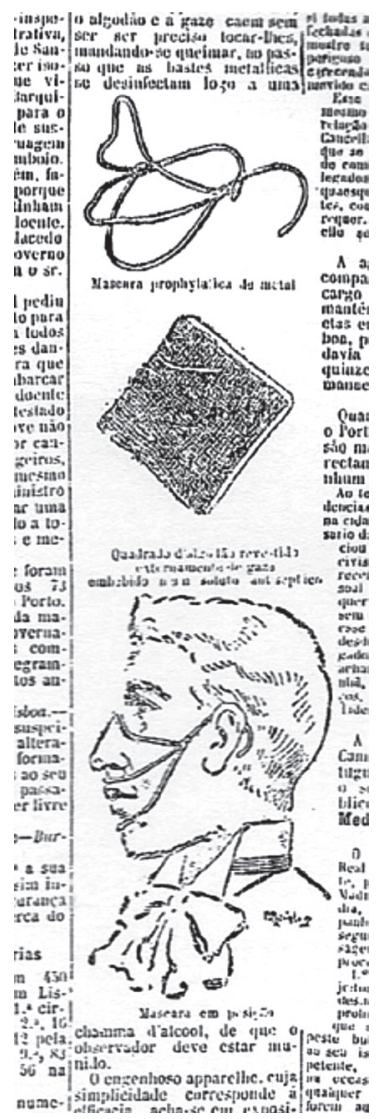

\section{Tifo exantemático, gripe pneumónica e varíola}

O ano de 1918 foi marcado pelo final da Primeira Guerra Mundial. Mas mais mortífera foi a epidemia de gripe pneumónica que se espalhou por todo o mundo e que provou ser "um dos piores flagelos epidémicos da história humana", que matou entre 50 e 100 milhões de pessoas ${ }^{30}$. No Porto, esta epidemia encontrou uma população já extremamente debilitada pelas

${ }^{30}$ SOBRAL, José Manuel, LIMA, Maria Luísa, CASTRO, Paula e SOUSA, Paulo Silveira e (orgs.) - A Pandemia Esquecida. Olhares comparados sobre a Pneumónica 1918-1919. Lisboa: Imprensa de Ciências Sociais, 2009. 
doenças endémicas já descritas, agravadas pelas condições sanitárias que não tinham sido objeto de melhorias significativas.

Em dezembro de 1917 declarou-se uma epidemia de tifo exantemático no Porto. Logo em janeiro de 1918, na qualidade de Diretor-Geral da Saúde, Ricardo Jorge deslocou-se ao Porto para estudar o problema e colocar em prática as primeiras medidas sanitárias. Como resultado do seu inquérito local, elaborou um relatório que foi apresentado no Conselho Superior de Higiene, no qual desenvolveu a história e definição da doença e apresentou o plano das medidas destinadas ao seu combate naquela cidade e no país ${ }^{31}$. O seu plano sanitário foi colocado em prática pelo Professor Augusto de Almeida Monjardino, nomeado comissário do governo na cidade do Porto para combate à epidemia no dia 23 de fevereiro de 1918, e depois pelo Professor António de Almeida Garrett, que o sucedeu no cargo e desde 18 de maio de 1918 dirigiu o combate à epidemia de tifo exantemático que se prolongou até ao ano seguinte ${ }^{32}$. Em simultâneo o comissário do governo teve de lidar com a epidemia de gripe pneumónica que grassou desde agosto desse $\mathrm{ano}^{33}$.

Se as medidas sanitárias tomadas para evitar a propagação do tifo exantemático foram muito semelhantes às da peste bubónica de 1899, com os banhos obrigatórios e a desinfeção de roupas e casas para matar os piolhos transmissores da doença, o isolamento dos doentes e dos seus contatos mais imediatos, as visitas domiciliárias e a notificação obrigatória dos epidemiados, com a cidade dividida em áreas sanitárias e a obrigatoriedade de guias sanitárias para os viajantes (apenas não se criou o cordão sanitário), além da recomendação do recrutamento de tifosos curados para os serviços perigosos de despiolhamento, aproveitando a sua imunidade à doença ${ }^{34}$, pelo contrário, no que disse respeito à gripe, a sua propagação pelo ar tornou

${ }^{31}$ Diário de Notícias, 21/02/1918.

${ }^{32}$ ALMEIDA, Maria Antónia Pires de - António de Almeida Garrett. Biografias de Cientistas e Engenheiros Portugueses. Lisboa: CIUHCT (2011), (http://ciuhct.com/index. $\mathrm{php} / \mathrm{pt} /$ biografias/335-garret-antonio-de-almeida.html, consultado em 2012.06.08)

33 A publicação oficial do diagnóstico desta epidemia foi em 31/08/1918, Diário de Notícias, 25/09/1918.

${ }^{34}$ SOUSA, Paulo Silveira e, SOBRAL, José Manuel, LIMA, Maria Luísa, CASTRO, Paula-A epidemia antes da pandemia: o tifo exantemático no Porto (1917-1919) in SOBRAL, José Manuel et all (orgs.), A Pandemia Esquecida ... cit., p. 279-290. 
desnecessárias medidas restritivas à circulação de pessoas. Aconselhou-se apenas "evitar a permanência em lugares fechados onde haja grandes aglomerações (...) devem arejar-se largamente as habitações e lugares de trabalho. É para aconselhar o uso de preparações desinfetantes das vias nasais e garganta" e tornou-se "obrigatória a declaração por escrito de todos os

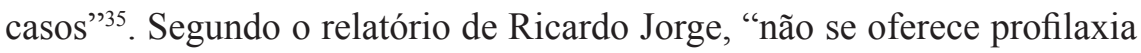
efetiva e eficaz a exercer contra tal epidemia que não seja a higiene geral e assistência dos atacados preferentemente em hospital de isolamento"36. Mais tarde as feiras e mercados foram proibidos e as escolas só iniciaram o ano letivo depois do dia 28 de novembro. Em simultâneo, entre junho e dezembro de 1918 verificou-se uma epidemia de varíola que obrigou a um movimento de vacinação rigorosíssimo em todo o país.

A publicidade refletiu a chegada da gripe: um anúncio de muito repetido de xarope para a tosse alterou o seu texto, passando imediatamente a ser um xarope para a gripe.

Figura IV - Anúncios, O Comércio do Porto, 31/08/1918 e 28/09/1918
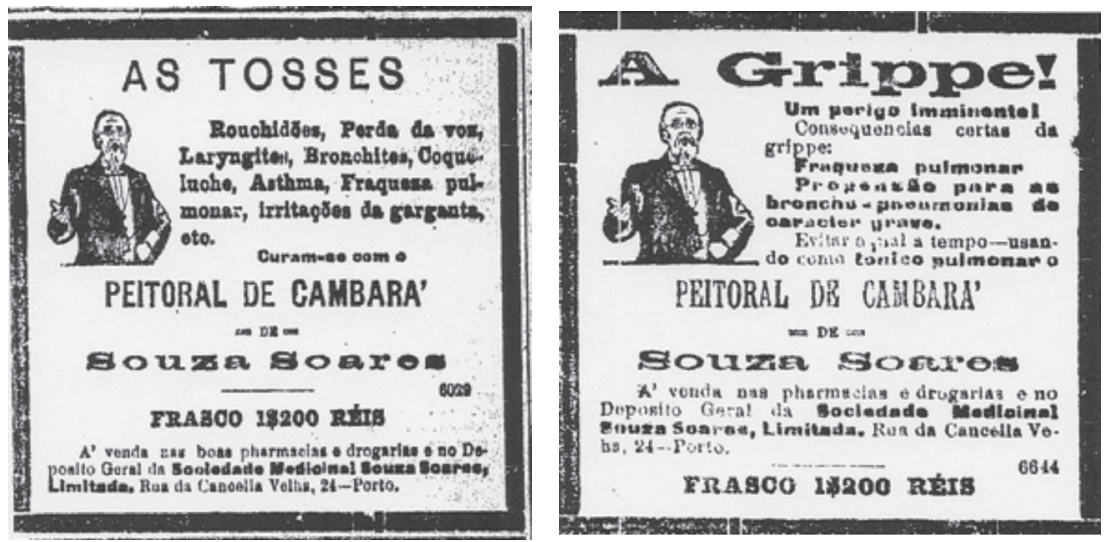

Na sequência destas epidemias, Ricardo Jorge participou em conferências internacionais, como a da Comissão Sanitária dos Países Aliados, que se realizou em Paris em abril de $1918^{37}$ e também no ano seguinte, em março, apresentou à mesma comissão um relatório sobre a gripe; em outubro de

\footnotetext{
${ }^{35}$ O Comércio do Porto, 15/06/1918.

${ }^{36}$ O Comércio do Porto, 25/09/1918.

${ }^{37}$ Diário de Notícias, 10/04/1918.
} 
1919 apresentou uma comunicação ao Comité Internacional de Higiene Pública sobre o tifo exantemático no Porto, na qual reafirmou que o piolho, agente responsável pela transmissão da doença, era ainda muito frequente nas classes mais pobres, também as mais afetadas. Estes relatórios foram publicados respetivamente em 1919 e $1920^{38}$.

Apesar do intenso trabalho de Ricardo Jorge, o processo de transição sanitária teria lugar em Portugal apenas a partir da década de 1920, em flagrante atraso relativamente a outros países europeus. Porém, só se consolidaria definitivamente na década de 1950, época em se pode afirmar que a transição epidemiológica estava terminada ${ }^{39}$.

\section{Resumo do tema}

Em todos os momentos epidémicos descritos, um fator foi sempre salientado nas notícias, independentemente do estado dos conhecimentos médico-farmacênticos das respetivas épocas: a higiene. Repetem-se desde os meados do século XIX as preocupações com a limpeza e arejamento das casas, das roupas, dos móveis e do corpo dos doentes. Curiosamente as referências à lavagem das mãos estão praticamente ausentes, mesmo em 1918.

Verifica-se que o pessoal médico e as autoridades oficiais estavam informados das mais recentes novidades científicas. A imprensa diária demonstrou esta situação e provou-nos que a circulação do conhecimento era uma realidade, por meio da divulgação de livros, transcrições e traduções de revistas especializadas, comentários das obras mais recentes. Sabemos também que os médicos e cientistas portugueses participavam em conferências científicas internacionais e realizavam viagens de estudos aos melhores laboratórios e centros de conhecimento europeus. No entanto, esse conhecimento restringia-se aos grandes centros. Era um facto a pouca

38 JORGE, Ricardo - La grippe: rapport préliminaire présenté à la commission sanitaire des pays alliés dans sa session de mars 1919. Lisbonne: Imp. Nationale, 1919. IDEMLe typhus exanthématique à Porto, 1917-1919: communication faite au Comité international d'hygiéne publique dans sa session d'Octobre 1919. Lisbonne: Imp. Nationale, 1920.

${ }^{39}$ SOUSA, Paulo Silveira et all, cit. 


\begin{tabular}{|c|c|c|}
\hline 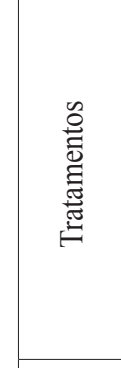 & 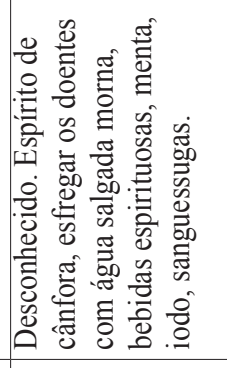 & 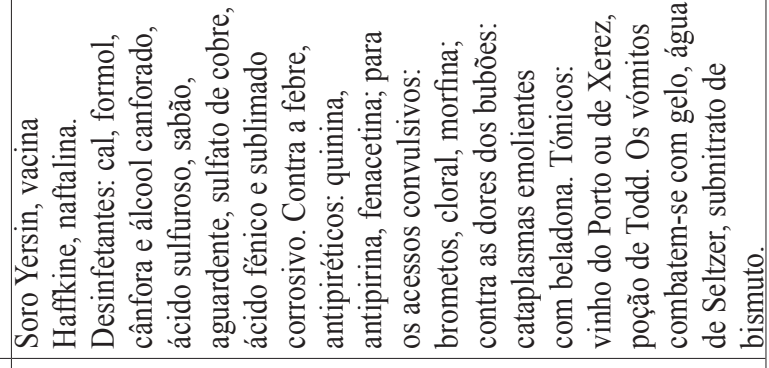 \\
\hline 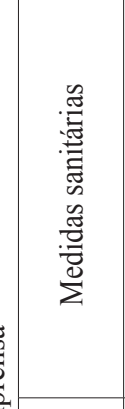 & 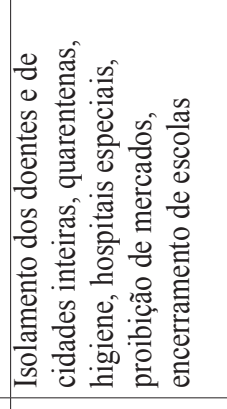 & 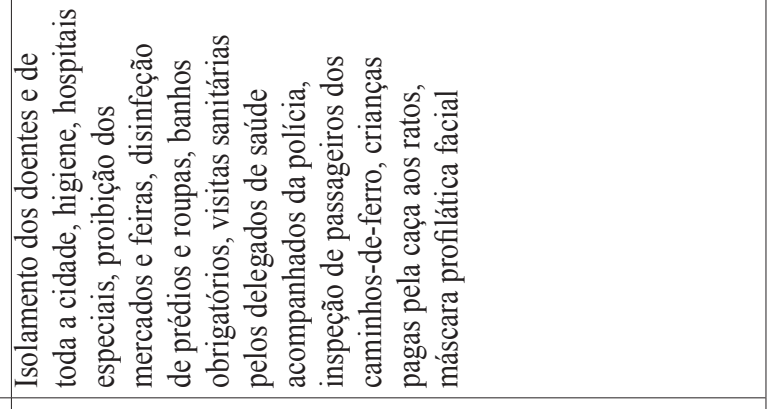 \\
\hline & 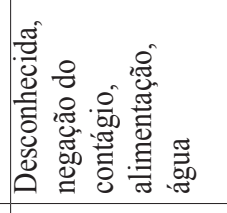 & 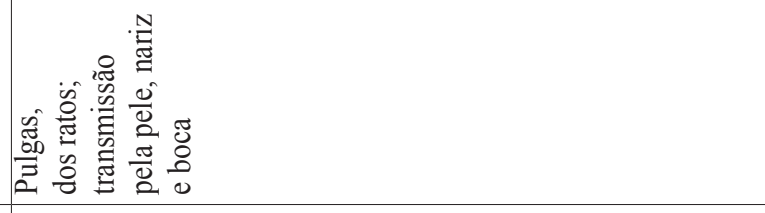 \\
\hline 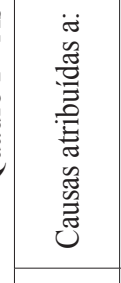 & \multicolumn{2}{|c|}{ 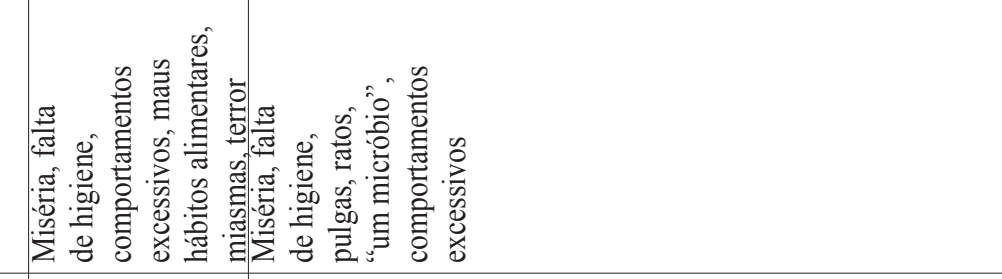 } \\
\hline 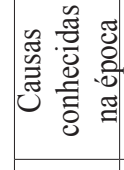 & & 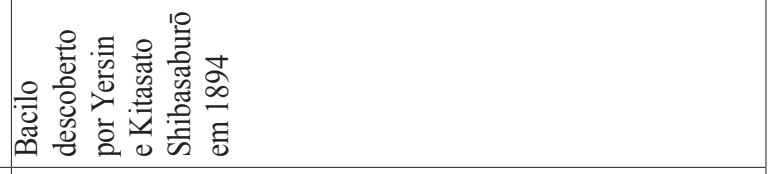 \\
\hline$\sum_{\substack{0 \\
\vdots}}^{\infty}$ & 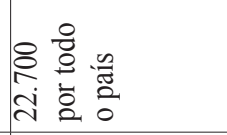 & 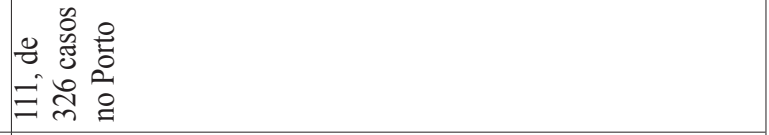 \\
\hline 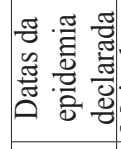 & & 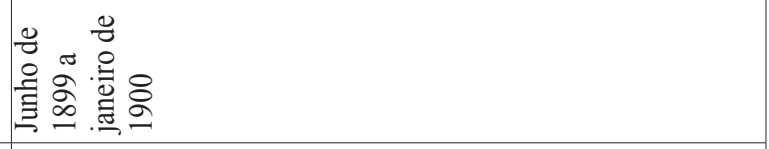 \\
\hline 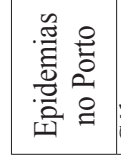 & 苟 & 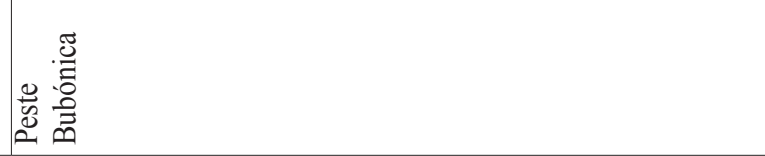 \\
\hline
\end{tabular}




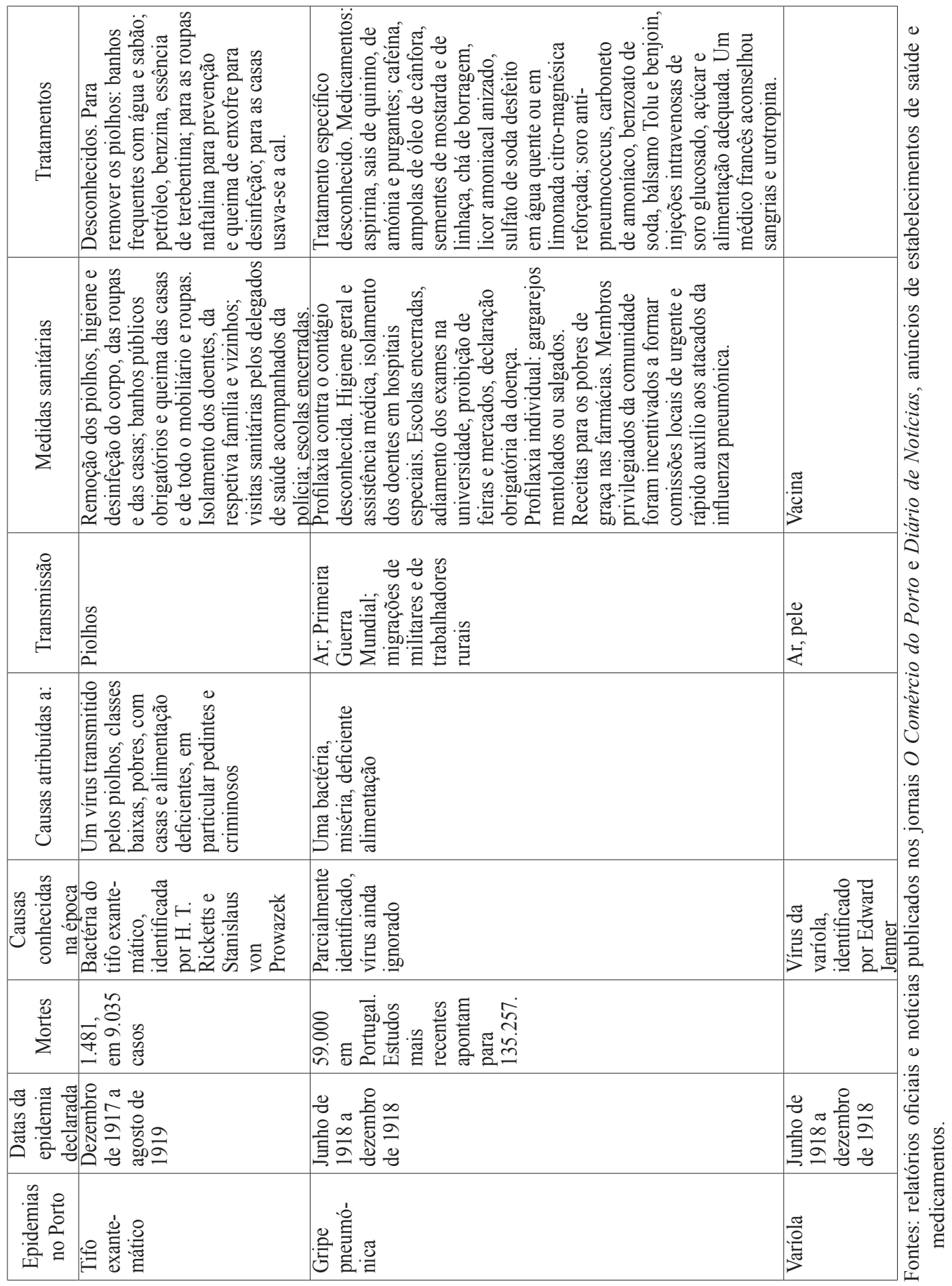


disponibilidade dos melhores profissionais para se deslocarem à província, onde faltavam meios, equipamentos e medicamentos para acudir às populações. Ao longo do período analisado foi clara a evolução dos conhecimentos e das práticas médicas e a diferença entre as medidas sanitárias impostas.

Outro fator comum em todas as epidemias descritas relaciona-se com a injustiça da aplicação das medidas sanitárias e as falhas na sua aplicação, que resultavam na sua ineficácia. Como consequência, a negação da epidemia, para que as restrições fossem imediatamente levantadas. O medo e o terror são também fatores recorrentes, assim como a questão moral da doença e o fator comportamental: a epidemia como castigo para comportamentos excessivos e desregrados. Esta é uma herança religiosa que a ciência absorveu e ainda não nega, pois incorporou-a no seu discurso. A higiene e o comportamento socialmente repreensível aparecem sempre associados à doença e está presente o fator culpa. Em todos estes casos, a imprensa revelou-se uma fonte histórica indispensável. Perante as considerações expostas e os exemplos apresentados, a hipótese de que a imprensa generalista portuguesa do século XIX e início do século XX tinha a intenção de educar e formar o público leitor e ouvinte parece-nos perfeitamente identificada e comprovada. 